\title{
Desempenho de um motor de trator agrícola em bancada dinamométrica com biodiesel de óleo de frango e misturas binárias com óleo diesel
}

\author{
Performance of an agricultural tractor engine in dynamometer with chicken oil biodiesel and binary \\ mixtures with diesel oil
}

\author{
Diego Augusto Fiorese ${ }^{\mathrm{I}, \text { III }}$ Arno Udo Dallmeyer ${ }^{\mathrm{II}}$ Leonardo Nabaes Romano ${ }^{\text {II }}$ \\ José Fernando Schlosser ${ }^{I}$ Paulo Romeu Moreira Machado II
}

\section{RESUMO}

O Brasil, terceiro maior produtor de biodiesel do mundo e terceiro maior produtor mundial de frango, pode incrementar, na sua matriz energética, o uso de óleo oriundo de aves como alternativa aos combustíveis fósseis e à redução da dependência do óleo de soja para esse fim. O país dispõe de mais de 350 milhões de litros de óleo de frango por ano. Considerando a aplicação dos combustíveis alternativos para os motores a diesel, em máquinas agrícolas, o trabalho teve por objetivo avaliar o desempenho do motor de um trator agrícola de $53 \mathrm{~kW}$ acoplado pela TDP em bancada dinamométrica, operando com biodiesel metílico de óleo de frango e misturas com óleo diesel, sendo: B5 (testemunha), B20, B40, B60, B80 e B100. Avaliaram-se a potência, o torque, a reserva de torque, o consumo de combustível, o consumo de energia e a eficiência térmica do motor. $O$ ensaio foi instalado com delineamento inteiramente casualizado (DIC) em esquema fatorial com seis tratamentos. Os resultados foram submetidos à análise de variância e as médias ajustadas por equações de regressão. Foram observadas perdas na geração de potência e torque, aumento no consumo de combustível, redução do consumo energético e melhoria na eficiência térmica do motor, de acordo com o aumento da proporção de biodiesel na mistura.

Palavras-chave: biocombustível, ensaio, eficiência, dinamometria.

\section{ABSTRACT}

Brazil, the world third largest producer of biodiesel, and also the third largest producer of chicken, may increase the energy matrix, using oil derived from chicken, as an alternative to fossil fuels and reduce dependence on soybean

\begin{abstract}
oil for this purpose. The country can produce over 350 million liters of chicken oil per year. Considering the application of alternative fuels on diesel engines in agricultural machinery. The study aimed to evaluate the performance of a engine agricultural tractor with $53 \mathrm{~kW}$ coupled by PTO in dynamometer bench operating with methyl biodiesel oil chicken and mix with diesel oil. Fuels B5 (reference), B20, B40, B60, B80 and B100 mixtures were used. The power, torque, torque reserve, fuel consumption, energy consumption and thermal efficiency of the engine were evaluated. The trial was conducted with a completely random design (CRD) in a factorial design with six treatment, which was held after the analysis of variance and adjusted means for the regression equations. Losses were observed in the generation of power and torque, increase in fuel consumption, reduction of energy consumption and improvement in engine thermal efficiency, according to the increasing proportion of biodiesel in the blend.
\end{abstract}

Key words: biofuel, test, efficiency, dynamometry.

\section{INTRODUÇÃO}

No Brasil, os combustíveis líquidos representam quase $60 \%$ da matriz energética e, destes, $45 \%$ são consumidos na forma de óleo diesel (ANP, 2010). Desde 2005, o país fomenta a inclusão gradativa de combustíveis alternativos ao óleo diesel, com ênfase a óleos e gorduras vegetais e animais. Denomina-se biodiesel o combustível renovável e biodegradável, constituído de uma mistura de ésteres metílicos ou

I'Programa de Pós-graduação em Engenharia Agrícola (PPGEA), Departamento de Engenharia Rural, Universidade Federal de Santa Maria (UFSM), Santa Maria, RS, Brasil.

"Departamento de Engenharia Mecânica, UFSM, Santa Maria, RS, Brasil.

IIIDepartamento de Engenharia Rural, Universidade Estadual Paulista (UNESP), Rua Dr. José Barbosa de Barros, 1780, 18610-337, Botucatu, SP, Brasil. E-mail: dafiorese@yahoo.com.br. Autor para correspondência. 
etílicos de ácidos graxos, obtidos a partir da reação química de transesterificação de qualquer triglicerídeo com um álcool de cadeia curta, normalmente o metanol ou o etanol (PARENTE, 2003).

A soja é a principal matéria-prima para produção de biodiesel no Brasil. Além desta, outras fontes devem ser estudadas para aumentar o leque de alternativas (PARENTE, 2003). Um estudo de amplitude regional foi realizado por GOMES et al. (2008), no intuito de identificar as possibilidades de produção de biodiesel de óleo de frango. Os autores concluíram que, em média, cada frango abatido produz 67,8g de óleo. Com este dado e baseando-se na estatística de produção anual de 2009, em que o Brasil produziu mais de 4,7 bilhões de aves (UBA, 2009), encontra-se o potencial estimado da produção de óleo de frango no Brasil, resultando em mais de 350 milhões de litros de óleo, podendo atender a mais de $15 \%$ do mercado de biodiesel do país, quando comparando com os dados da ANP (2010).

Com relação à aplicação dos combustíveis alternativos em motores diesel, deve-se pensar, entre outros aspectos, na manutenção do desempenho operacional. Para avaliação de desempenho, os motores de combustão interna devem ser submetidos a ensaios de plena carga, diretamente pelo volante do motor ou pela tomada de potência (TDP), no caso de tratores agrícolas. Para isso, o dinamômetro é o item mais importante num banco de provas de motores, e é utilizado para medir a potência, o torque e o consumo específico de combustível de um motor, além de oferecer subsídios para determinação de demais variáveis (STONE, 1999).

Estudos concluíram que não há perdas significativas no desempenho do motor quando operando com biodiesel ou misturas binárias, apresentando pouca redução na potência e no torque, e que a maior alteração é no consumo de combustível (COSTA \& OLIVEIRA, 2006; VOLPATO, 2009), não havendo necessidade de mudanças no motor (PINTO et al. 2005). A reserva de torque é calculada pelos valores extremos de torque e de potência máxima, na faixa de utilização do motor em plena carga. Nessa faixa, o motor apresenta funcionamento estável, se autoregulando pela ação da bomba injetora. A reserva acima de $15 \%$ é considerada boa, entre 10 e $15 \%$ regular e abaixo de 10\% ruim (MIALHE, 1996).

O conteúdo energético, representado pelo poder calorífico, é uma propriedade que demonstra a adequação dos vários tipos de compostos graxos para o uso como combustível diesel (CD). O poder calorífico contido nos ésteres alquílicos corresponde a aproximadamente $90 \%$ daquele observado no diesel de petróleo (KNOTHE et al., 2006). COSTA \& OLIVEIRA
(2006) enfatizaram que o biodiesel, apesar de possuir poder calorífico menor do que o diesel de petróleo, possui maior número de cetano (NC), especialmente os de origem animal, indicando melhor qualidade de combustão e, por consequência, aproveita melhor a energia contida no combustível, ressaltando PINTO et al. (2005) que o motor apresenta um maior rendimento energético.

O rendimento do motor define a eficiência com que o calor é transformado em trabalho. Dessa forma, a conversão da energia do combustível (potência teórica) em energia mecânica no volante (potência efetiva) é calculada de acordo com a potência de entrada e saída (MIALHE, 1996). Utilizando um trator de 57,37kW, acoplado pela TDP a um dinamômetro, foi verificado, por BARBOSA et al. (2008), que o motor apresentou menor consumo energético e melhor eficiência térmica, à medida que se aumentava a quantidade de biodiesel misturado ao óleo diesel.

Um dos principais objetivos de se utilizar a dinamometria é analisar a eficiência da conversão energética química de combustíveis em energia mecânica na forma de potência. Considerando tal premissa, o objetivo deste trabalho foi comparar o desempenho do motor de $53 \mathrm{~kW}(72 \mathrm{cv})$ de um trator agrícola operando com biodiesel de óleo de frango e misturas binárias com óleo diesel B5.

\section{MATERIAL E MÉTODOS}

O trabalho foi realizado nas instalações do Núcleo de Ensaios de Máquinas Agrícolas - NEMA, na Universidade Federal de Santa Maria - UFSM, Santa Maria/RS. Utilizou-se um trator agrícola marca Massey Ferguson, modelo 275 4x2, ano 1986, com motor 4 cilindros de injeção direta, marca Perkins, modelo p4000, capacidade volumétrica de $4100 \mathrm{~cm}^{3}$, $53 \mathrm{~kW}$ e potência máxima na TDP de 47kW; um dinamômetro de correntes parasitas (correntes de Foucault), modelo NL 480 da fabricante MWD; um medidor de fluxo, marca OVAL, modelo M-III LSF41L0-M2, alimentado por corrente contínua (12 24V) interligado a um registrador de dados (datalogger), marca Campbell Scientific, modelo CR 1000, acoplado a um computador portátil; balança digital de precisão para determinação da densidade dos combustíveis a $20^{\circ} \mathrm{C}$; e demais equipamentos auxiliares para garantir confiabilidade da captação de dados.

No dinamômetro NL 480, a potência de saída é absorvida pela interação eletro-magnética gerada entre o eixo rotor e o estator (carcaça). Na figura $1 \mathrm{~A}$, pode-se verificar o leiaute básico desse tipo de equipamento. O biodiesel de óleo de frango foi adquirido de uma planta experimental situada na região 


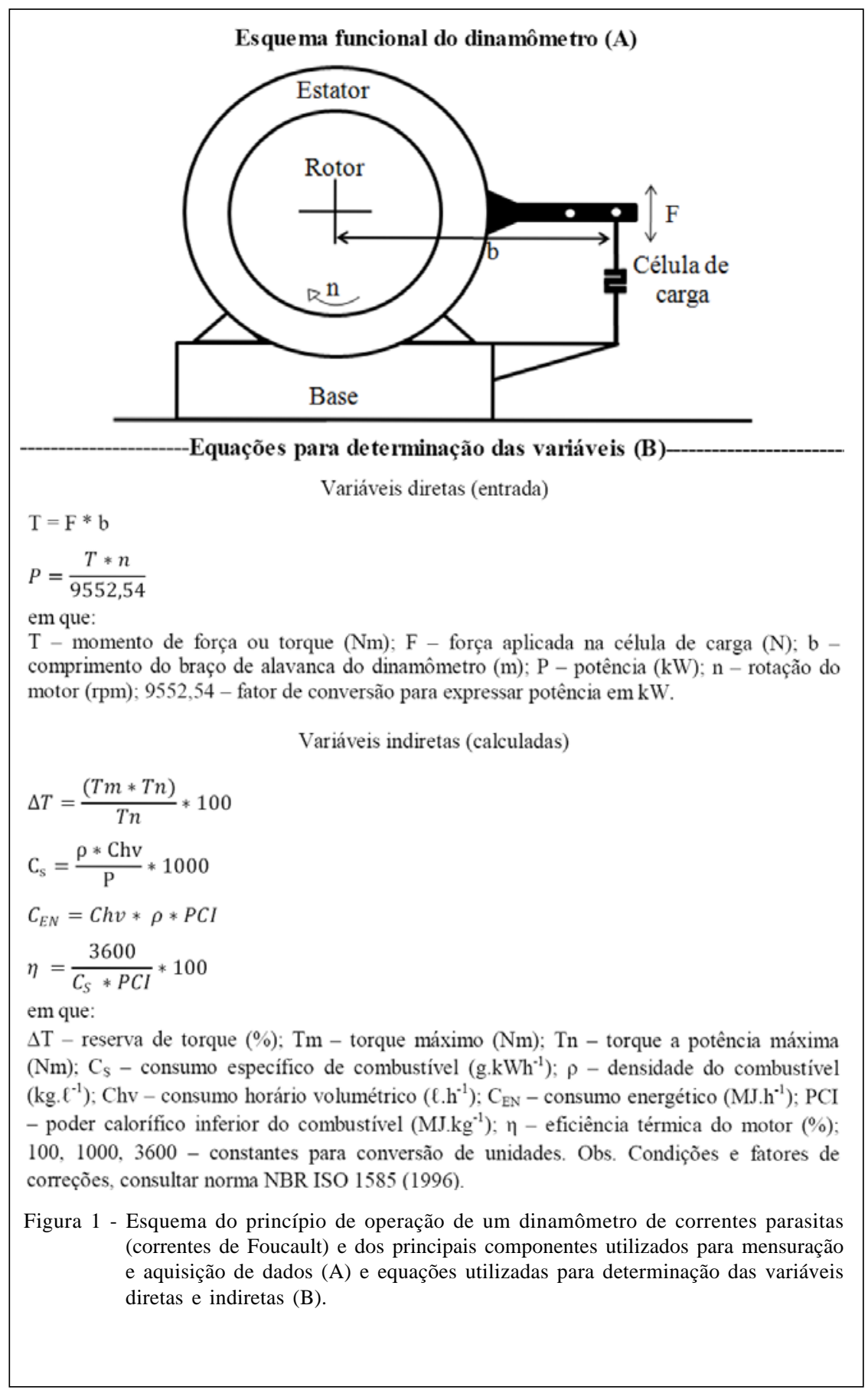

Oeste de Paraná, que adota o processo de transesterificação para conversão dos ésteres e atende às especificações de qualidade exigidas pela legislação vigente. As misturas adotadas foram B5 (testemunha), B20, B40, B60, B80 e B100, em que B = blend (mistura) e o número representa o valor percentual de biodiesel. No texto que segue, onde for possível, será adotado combustível(s) como sinônimo de mistura(s).
Os ensaios foram conduzidos conforme as normas ABNT NBR ISO 1585 (1996), e a metodologia para determinação das variáveis foi dividida em duas partes:

Primeira parte: obtenção das variáveis diretas, obtidas em baterias de ensaios com três repetições, sendo: potência $(\mathrm{P})$, torque $(\mathrm{T})$ e rotação (n) no dinamômetro; consumo horário volumétrico 
(Chv) com o medidor de fluxo e registrador de dados; densidade dos combustíveis a $20^{\circ} \mathrm{C}$ com balança de precisão e, por último, medição do poder calorífico inferior (PCI) dos combustíveis, realizada por empresa terceirizada.

Segunda parte: determinação das variáveis indiretas, sendo: consumo específico $\left(\mathrm{C}_{\mathrm{S}}\right)$; consumo energético $\left(\mathrm{C}_{\mathrm{EN}}\right)$ e eficiência térmica do motor $(\eta)$. Ambas as variáveis (diretas e indiretas) foram calculadas conforme identificado no quadro de equações da figura 1B.

O consumo específico é expresso em unidade de massa por unidade de potência $\left(\mathrm{g} \mathrm{kWh}^{-1}\right)$ e o consumo energético é expresso em unidade de energia por unidade de tempo, o que demonstra quanto de energia o motor está consumindo, ou seja, toda energia contida no combustível consumido, multiplicado pelo tempo de utilização $\left(\mathrm{MJ} \mathrm{h}^{-1}\right)$. A eficiência térmica foi determinada de acordo com HEYWOOD (1988), a partir do consumo específico e do PCI.

Com o trator acoplado pela TDP ao dinamômetro por arvore cardã, avaliou-se, na faixa de rotação de trabalho do motor, entre 1200 e 2100rpm. A absorção da potência aplicada pelo motor é calculada pelo software Accudyno, que fornece os dados corrigidos (NBR ISO 1585) a partir da rotação do motor e força aplicada à célula de carga. As curvas de potência e torque do motor foram geradas com o motor em plena carga, iniciando na rotação máxima do motor e reduzindo conforme a aplicação de carga pelo dinamômetro, sendo coletados dados a cada 100rpm até a rotação de $1200 \mathrm{rpm}$.

O delineamento experimental utilizado foi inteiramente casualizado (DIC), com seis tratamentos (combustíveis) na faixa de rotação entre 1200 e 2100rpm, em três repetições. Os dados resultantes para cada combustível foram submetidos à análise de variância em nível de $5 \%$ e as médias ajustadas por equações de regressão.

\section{RESULTADOS E DISCUSSÃO}

Os resultados correspondentes às densidades e ao poder calorífico inferior (PCI) para B5, B20, B40, B60, B80 e B100 foram, respectivamente: densidades: 0,$837 ; 0,845 ; 0854 ; 0,863 ; 0,871 ; 0,880 \mathrm{~kg} \mathrm{l}^{-1} \mathrm{e}$ PCI: 45,85; 44,54; 43,23; 41,92; 40,61; 39,30MJ h-1. O biodiesel de óleo de frango possui maior densidade e o PCI é 14,29\% menor que do óleo diesel B5. Houve redução da potência e do torque e aumento do consumo de combustível em função da redução do PCI (aumento da proporção de biodiesel), melhor explicado pelo fato de ter havido a redução gradativa do conteúdo energético.

Observando-se as curvas originais de potência e torque, para a testemunha (B5) e B100 (Figura 2, A), verifica-se o afastamento das curvas, o que indica pequenas alterações no comportamento do motor. A potência máxima foi identificada em 1900rpm e o torque máximo em 1200rpm para B5, B20 e B40 e em 1300rpm, para B60, B80 e B100. O torque máximo é desenvolvido em rotações em que há uma melhor combinação entre o escoamento de ar (comburente), injeção de combustível e qualidade de ignição e combustão, favorecendo a liberação de energia e, consequentemente, desenvolvendo maior força sobre o pistão, e maior torque no virabrequim do motor. No caso dos CD, a característica que está relacionada com a qualidade de ignição é o NC, de forma que, quanto maior o valor do NC, mais eficiente é o processo de combustão do combustível, permitindo, assim, que o torque máximo seja atingido em rotações mais elevadas, momento em que o tempo para a completa combustão do combustível é menor.

O comportamento da potência máxima e o torque máximo apresentaram ajuste linear decrescente desenvolvendo menos potência e torque, conforme o aumento da proporção de biodiesel. O mesmo acontece com a reserva de torque, que é um fator calculado de acordo com torque máximo e nominal do motor (Figura 2, B e C). O comportamento do consumo se apresenta de forma oposta à redução do poder calorífico, ou seja, maior é o consumo de combustível, volumétrico e específico, quanto menor for o conteúdo de energia no combustível. Confirmando o pressuposto, observouse efeito linear crescente em sentido ao aumento de biodiesel na mistura, identificado na figura 3D.

Os resultados de potência, torque e consumo de combustível são concordantes com os relatos de COSTA \& OLIVEIRA(2006) e VOLPATO et al. (2009). A reserva de torque mínima de um motor deve estar entre 10 e 15\%, conforme relatado por MIALHE (1996). Os resultados médios mostraram que somente operando com óleo diesel B5 é que foi possível manter o motor dentro dessa classificação, com um valor de $10,69 \%$. 


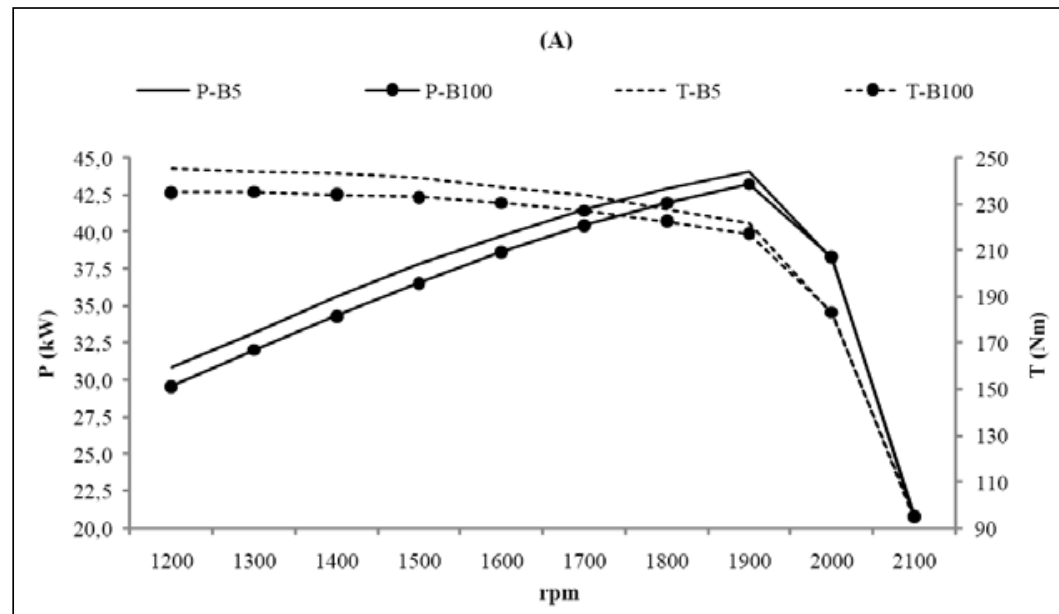

(B)

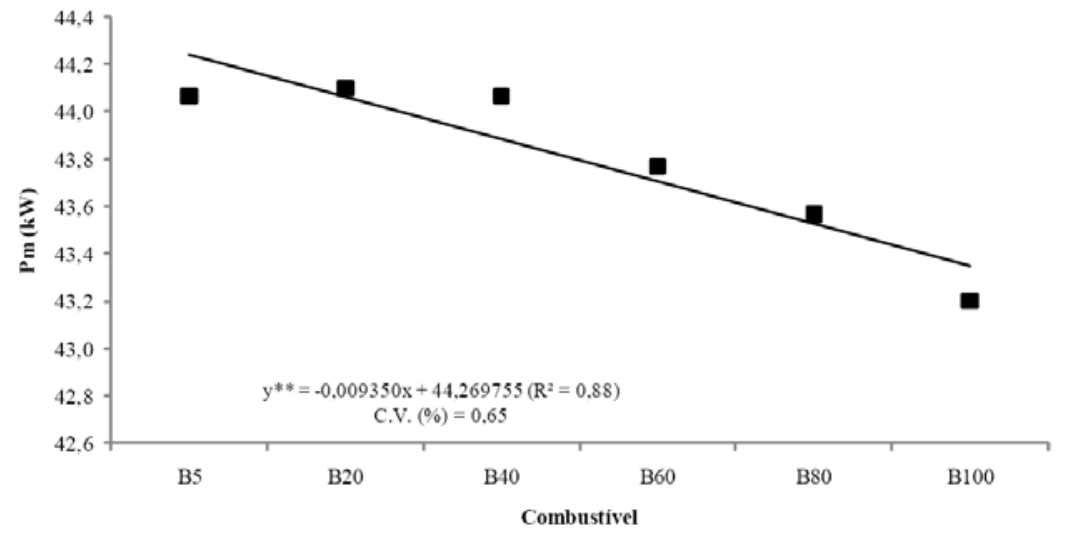

(C)

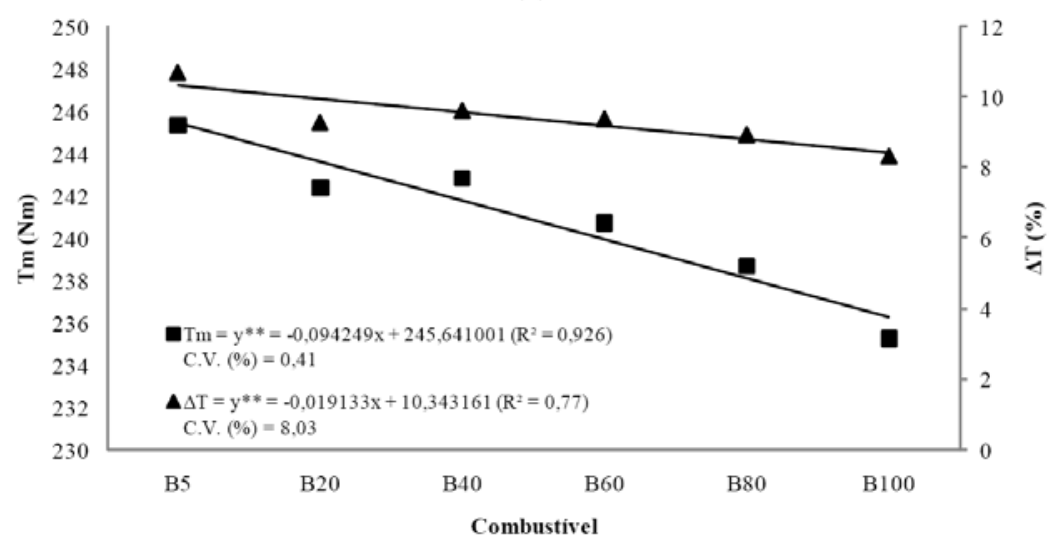

Figura 2 - Curvas originais de potência e torque para B5 e B100 (A), e potência máxima (B), torque máximo e reserva de torque (C), do motor do trator MF 275 ensaiado em dinamômetro (acoplado pela TDP), operando com todos os combustíveis avaliados (B5, B20, B40, B60 B80 e B100).

Considerando as médias de cada combustível, nas rotações de 1200 a 2100rpm, observou-se um ajuste linear decrescente para o consumo energético, e crescente para a eficiência do motor (Figura 3, E e F). Houve efeito significativo do aumento de biodiesel na mistura, para redução do consumo de energia e para aumento da eficiência térmica do motor. Esse comportamento se deve ao melhor aproveitamento do conteúdo energético, devido ao maior NC, induzindo à melhor qualidade de ignição 


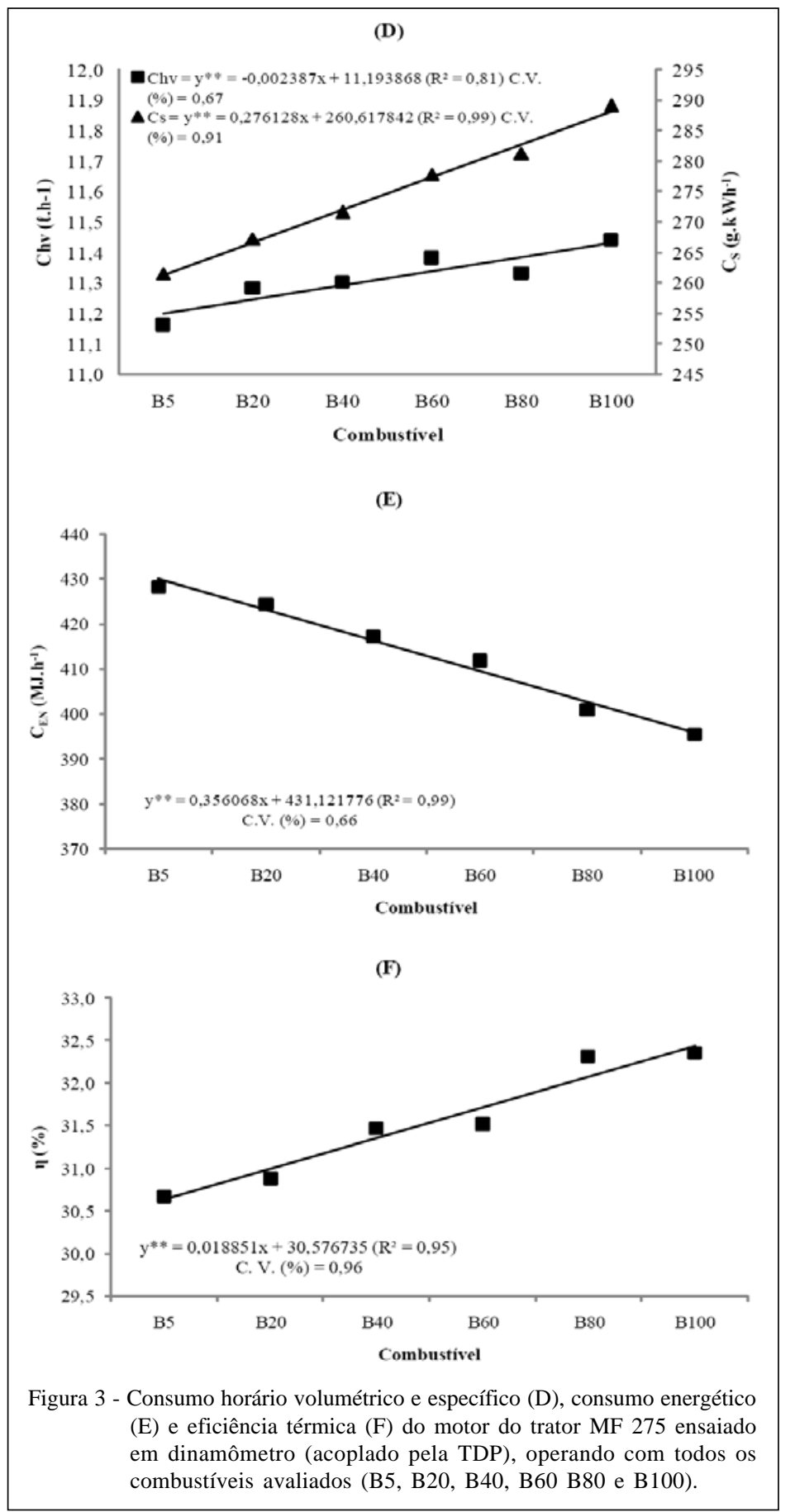

e combustão do biodiesel. Fator que também justifica os efeitos de melhoria na eficiência do motor operando com biodiesel, provém da redução do atrito das partes móveis e estáticas do motor, devido à ação de lubrificação que o biodiesel detém, quando comparado com óleo diesel B5. Esses resultados são semelhantes com os relatos de PINTO et al. (2005), COSTA \& OLIVEIRA (2006) e BARBOSA et al. (2008).

\section{CONCLUSÃO}

A adição de biodiesel reduziu o consumo energético e aumentou a eficiência térmica do motor, passando de 30,67\% com B5 (testemunha) para 32,35\% com B100. A melhoria da eficiência do motor não foi suficiente para manter a potência, o torque e o consumo de combustível nos mesmos patamares que a 
testemunha (B5), apresentando comportamento linear conforme aumento da proporção de biodiesel. Houve redução de 2,01\% na potência máxima, 4,29\% no torque máximo e aumento de $9,56 \%$ no consumo específico de combustível, fatores influenciados pelo menor poder calorífico do biodiesel.

\section{REFERÊNCIAS}

ABNT. ASSOCIAÇÃO BRASILEIRA DE NORMAS TÉCNICAS. Veículos rodoviários - Código de ensaio de motores Potência líquida efetiva. Método de ensaio NBR ISO 1585. Rio de Janeiro, 1996. 26p.

ANP. AGÊNCIA NACIONAL DO PETRÓLEO GÁS NATURAL E BIOCOMBUSTÍVEIS (Brasil). Dados estatísticos mensais. Brasília-DF, 2010. Disponível em: <http://www.anp.gov.br/ ?pg $=37675 \& \mathrm{~m}=\& \mathrm{t1}=\& \mathrm{t} 2=\& \mathrm{t} 3=\& \mathrm{t} 4=\& \mathrm{ar}=\& \mathrm{ps}=\& \mathrm{cach}$ hust=1291049592468 $>$. Acesso em: 29 nov. 2010.

BARBOSA, R.L. et al. Desempenho comparativo de um motor de ciclo diesel utilizando diesel e misturas de biodiesel. Ciência e Agrotecnologia, Lavras, v.32, n.5, p.1588-1593, 2008. Disponível em: <http://www.scielo.br/pdf/cagro/v32n5/35.pdf>. Acesso em: 10 fev. 2011. doi: 10.1590/S141370542008000500035 .

COSTA, B.J.; OLIVEIRA, S.M.M. de. Produção de biodiesel. Dossiê técnico. Curitiba: TECPAR, 2006. 27p. Disponível em: <http://www.sbrt.ibict.br/dossies-tecnicos>. Acesso em: 10 dez. 2010

GOMES, L.F.S. et al. Biodiesel produzido com óleo de frango. Acta Sciantiarum Technology, Maringá, v.30, n.1, p.57-62,
2008. Disponível em: <http://periodicos.uem.br/ojs/index.php/ ActaSciTechnol/article/view/3203/1941>. Acesso em: $10 \mathrm{dez}$. 2010. doi: 10.4025/actascitechnol.v30i1.3203.

KNOTHE, G. et al. Manual de biodiesel. Curitiba: Edgard Blücher, 2006. 340p.

HEYWOOD, J.B. Internal combustion engines Fundamentals. 2.ed. New York: McGraw-Hill, 1988. 897p.

MIALHE, L.G. Máquinas agrícolas: ensaios \& certificações. Piracicaba: CNPq-PADCT/TIB-FEALQ, 1996. $722 \mathrm{p}$.

PARENTE, E.J.S de. Biodiesel: uma aventura tecnológica num país engraçado. Fortaleza: Tecbio, 2003. 66p.

PINTO, A.C. et al. Biodiesel: an overview. Journal of Brazilian Chemical Society, São Paulo, v.16, n.6B, p.13131330, 2005. Disponível em: <http://www.scielo.br/pdf/jbchs/ v16n6b/27326.pdf >. Acesso em: 21 fev. 2011. doi: 10.1590/ S0103-50532005000800003.

STONE, R. Introduction to internal combustion engines. 6.ed. United States of America: SAE, 1999. 574p.

UBA. UNIÃO BRASILEIRA DE AVICULTURA. Relatório anual 2009. 2009. Disponível em: <http://www.abef.com.br/ noticias_portal/exibenoticia.php?notcodigo $=2041>$. Acesso em: 22 ago. 2010.

VOLPATO, C.E.S. et al. Desempenho de motor diesel quatro tempos alimentado com biodiesel de óleo de soja (B100). Ciência e Agrotecnologia, Lavras, v.33, n.4, p.1125-1130, 2009. Disponível em: <http://www.scielo.br/pdf/cagro/v33n4/ a25v33n4.pdf>. Acesso em: 21 fev. 2011. doi: 10.1590/S141370542009000400025 . 